\title{
Competências Matemáticas No Ensino Fundamental E Sugestão De Indicativos Para A Elaboração De Uma Proposta De Currículo Para A $15^{\mathrm{a}}$ Cre A Fim De Desenvolvê-Las
}

\author{
Mathematical Competences In Fundamental Teaching And \\ Indicative Suggestions For The Preparation Of A Curriculum Proposal For \\ The $15^{\mathrm{a}}$ Cre To Develop Them
}

\author{
Simone Fátima Zanoello \\ Universidade Regional Integrada do Alto Uruguai e das Missões - (URI - Erechim) \\ Claudia Lisete Oliveira Groenwald \\ Universidade Luterana do Brasil - (ULBRA- Canoas)
}

\begin{abstract}
Resumo
Este artigo é um recorte de uma tese de doutorado, a qual é um estudo de caso com foco na $15^{\text {a }}$ Coordenadoria Regional de Educação (CRE) do estado do Rio Grande do Sul. O presente trabalho tem como objetivo refletir sobre as competências que se espera que os alunos desenvolvam ao longo do Ensino Fundamental, bem como apresentar indicativos para uma proposta de currículo que privilegie o desenvolvimento de tais competências em alunos dos Anos Finais do Ensino Fundamental da região da $15^{\mathrm{a}} \mathrm{CRE}$, na área da Matemática. A partir da análise dos dados coletados e do estudo do referencial teórico, sugere-se, como indicativos para a elaboração de uma proposta de currículo, maior incentivo aos professores, por parte dos gestores das escolas, para que os docentes ampliem a sua formação, participando de formações continuadas e eventos; que toda a comunidade educativa participe da definição das competências que esperam que os alunos egressos desse nível de ensino possuam; e que a escola seja em turno integral, sendo que, no turno da manhã se trabalhem as disciplinas em salas-ambiente e, à tarde, sejam oferecidas oficinas variadas levando-se em consideração os diferentes interesses dos alunos.
\end{abstract}

Palavras-chave: Currículo. Anos Finais do Ensino Fundamental. Competências. $15^{\mathrm{a}}$ CRE.

\begin{abstract}
This article is a cutout of a doctoral thesis, which is a case study focused on the 15th Regional Education Coordination (CRE) of the state of Rio Grande do Sul. This work aims to reflect upon the competences that are expected students to develop throughout Primary School, as well as to present indicatives for a curriculum proposal that might privilege the development of such competences in students of Final Years of Elementary School in the region of the 15th CRE in Mathematics. Based on the analysis of the data collected and the study of the theoretical reference, it is suggested a greater incentive for teachers, by school managers, so that teachers can increase their education, participating in ongoing training and events, as an indicative for the elaboration of a curriculum proposal; that the entire educational community should participate in the definition of the competences that it is expected the students from this level of education to possess; and that the school be full-time, so that in the morning shift the disciplines are worked in classrooms and in the afternoon, various workshops are offered taking into account the different interests of the students.
\end{abstract}

Keywords: Curriculum; Final Years of Elementary Education; Skills; 15th CRE. 


\section{Introdução}

Com o passar dos anos, especialmente na última década do século passado e primeira deste, vieram à tona diversas insatisfações com relação aos sistemas educacionais, como se observa nos documentos elaborados pela OCDE (Organização para a Cooperação e Desenvolvimento Econômico), dentre os quais se destacam DeSeCo (Definição e Seleção de Competências-Chave) e PISA (Programa Internacional de Avaliação de alunos).

Dificuldades em preparar cidadãos competentes para agir adequadamente nas diferentes situações cotidianas fazem emergir a necessidade de discutir sobre o planejamento curricular que os estudantes necessitam para viver na sociedade atual.

Diante disso, o objetivo central deste artigo é refletir sobre o conjunto de competências que se espera que os alunos desenvolvam ao longo do Ensino Fundamental, bem como apresentar indicativos para uma proposta de currículo que privilegie o desenvolvimento de competências para os alunos dos Anos Finais do Ensino Fundamental da região da $15^{\mathrm{a}} \mathrm{CRE}$, no estado o Rio Grande do Sul, na área da Matemática.

A fim de atingir os objetivos, o presente artigo reflete inicialmente sobre o conjunto de competências que se espera que o aluno egresso do Ensino Fundamental possua, tanto em âmbito geral quanto no que tange à área da Matemática. Posteriormente, apresenta uma sugestão de indicativos para uma proposta de currículo que privilegie o desenvolvimento de tais competências em alunos dos Anos Finais do Ensino Fundamental da região investigada.

\section{Competências}

A partir da leitura de Perrenoud (2013), Perrenoud et al. (2007), Le Boterf (1994 apud PERRENOUD, 2013), Machado (2010), OCDE (2006), projeto DeSeCo (OCDE, 2002), Marco Comum Europeu de Referência para as Línguas (CONSEJO EUROPEO, 2001), Gómez (2011) e Argundín (2007), entende-se que competência é a capacidade de mobilizar conceitos, procedimentos e atitudes para executar uma ação de forma eficaz.

O aprendizado de conceitos, procedimentos e atitudes nem sempre é atingido em um curto espaço de tempo e deve ser tarefa de todas as disciplinas, sendo, portanto, necessário que os professores se reúnam e elaborarem um planejamento conjunto de forma inter ou até transdisciplinar, porque, segundo Goded (1994, p. 83), para: 
[...] compreender um conceito matemático e desenvolver competências e procedimentos matemáticos requer explorar o conhecimento matemático por extensão e aplicação em situações variadas, não é possível obter sua compreensão completa por dedução lógica ou definição única, é um conhecimento que alcança seu significado máximo em um processo contínuo de espiral, ampliando o campo de aplicação se aumenta sua compreensão e se desenvolvem maiores competências de interpretação e intervenção nas situações, e permite ampliar este novo campo de aplicação de uma forma de interação contínua entre modelo-objeto. Steinbring (1991) descreve esta necessária relação em situações concretas através do princípio da complementariedade do conhecimento matemático. (Tradução nossa).

Zabala e Arnau (2010) e o relatório da UNESCO - Um Tesouro a Descobrir (DELORS, 1996) defendem que a escola deve ter como meta desenvolver o aluno como um todo e, para que isso aconteça, acreditam que o currículo deve ser organizado a partir de competências básicas.

O termo "competências básicas" pode ser empregado também como: competências finais, competências essenciais, competências-chave, competências gerais ou competências transversais, entendendo-se competências básicas como um conjunto de conhecimentos, habilidades e atitudes que dão suporte para a resolução dos problemas que a vida apresenta e que são essenciais para viver em sociedade.

Diante disso, faz-se necessário refletir sobre as competências básicas para o aluno egresso do Ensino Fundamental.

\subsection{Refletindo Sobre As Competências Que Os Alunos Do Ensino Fundamental Precisam Desenvolver}

Zabala e Arnau (2010) mencionam que, para desenvolver os alunos como um todo, deve-se desenvolver atividades nos âmbitos social, interpessoal, pessoal e profissional. $\mathrm{O}$ relatório da Unesco - Um Tesouro a Descobrir (DELORS, 1996), outra fonte de referência, menciona que a educação deve ser desenvolvida a partir de quatro pilares: aprender a conhecer, aprender a ser, aprender a fazer e aprender a conviver (viver junto).

As nomenclaturas apresentadas no documento ou pelos autores Zabala e Arnau (2010) diferem, porém os significados são próximos. Nesta investigação assumimos os termos propostos pelo Relatório da UNESCO - Um Tesouro a Descobrir (DELORS, 1996), pois se acredita que os mesmos explicitam com clareza os âmbitos em que os alunos devem se desenvolver para que se tornem cidadãos competentes e atuantes na sociedade atual: ser, 
conhecer, conviver e fazer.

Aprender a conviver implica o aluno saber se relacionar, se comunicar e viver positivamente com os demais, independente de raça, etnia, cooperando e participando em todas as atividades com atitudes de compreensão, tolerância e solidariedade. Aprender a conviver também implica a participação ativa dos cidadãos na sociedade, procurando intervir de maneira crítica, responsável, visando a uma sociedade justa e democrática.

Aprender a ser implica o aluno ser competente para exercer, de forma responsável e crítica, a autonomia, a cooperação, a criatividade e a liberdade, por meio do conhecimento de si mesmo, da sociedade e da natureza em que vive. Que tenha valores, princípios, ética para viver bem consigo mesmo. Somente quando o aluno se desenvolver de forma pessoal e social, estando de bem consigo mesmo, ele conseguirá contribuir para a construção de uma sociedade democrática e solidária.

Aprender a conhecer compreende o domínio de conhecimentos, os quais possibilitarão que o aluno compreenda o mundo que o rodeia e seja atuante no desenvolvimento da sociedade. Porém, faz-se necessário que o aluno esteja aberto para aprender a aprender, já que os conhecimentos estão evoluindo constantemente.

Perrenoud (1999, p. 17) alerta: "Possuir conhecimentos ou capacidades não significa ser competente”. Tal ideia é reforçada por Salvador Llinares na palestra ¿Cómo dar sentido a las situaciones de enseñanza-aprendizaje de las matemáticas? Algunos aspectos de la competencia docente del professor, proferida na XIV Conferência Interamericana de Educação Matemática, quando afirma que, quando um aluno, ao resolver um problema, questiona se o mesmo é de mais ou de menos, significa que ele não é competente para resolver aquele problema, podendo ser competente para resolver o algoritmo da adição ou subtração.

Complementando esta afirmação, Perrenoud (1999, p. 18) afirma que:

- [...] a competência manifesta-se na ação, não é inventada na hora;

- se faltam os recursos a mobilizar, não há competência;

- se os recursos estão presentes, mas não são mobilizados em tempo útil e conscientemente, então, na prática, é como se eles não existissem.

Aprender a fazer implica o aluno conseguir integrar os conhecimentos científicos e técnicos aprendidos, os aspectos emocionais, saber trabalhar em equipe, ter organização, atitude e habilidades para executar determinada tarefa.

Referindo-se à disciplina de Matemática, o Pisa (OCDE, 2012, p. 7) afirma que competência Matemática é:

[...] uma capacidade do indivíduo para desenvolver, empregar e interpretar a Matemática numa variedade de contextos. Inclui raciocinar matematicamente 
e usar conceitos, procedimentos, fatos e ferramentas para descrever, explicar e prever fenômenos. Ajuda os indivíduos a reconhecer o papel da Matemática no mundo e fazer julgamentos bem fundamentados e tomar decisões necessariamente construtivas, engajadas e reflexivas. (Tradução nossa).

Ao referir-se à Matemática, identificam-se competências que podem ser exploradas por todos os blocos de conteúdos, e outras que são mais específicas a um dos blocos.

A partir dos Parâmetros Curriculares Nacionais (BRASIL, 1998), do documento "Princípios e Normas para a Matemática Escolar", produzido pelo National Council of Teachers of Mathematics (NCTM, 2008), identificam-se competências gerais da área da Matemática e que devem ser desenvolvidas por todos os blocos de conteúdos matemáticos:

- Resolver, tanto individualmente como em grupo, problemas da vida cotidiana, de outras Ciências ou da própria Matemática, utilizando diferentes estratégias e aplicando os resultados na resolução de novas situações.

- Identificar, relacionar, descrever e representar os elementos matemáticos presentes no dia a dia e no meio científico, analisando criticamente as informações que eles querem transmitir.

- Desenvolver o raciocínio lógico.

- Raciocinar e argumentar matematicamente, elaborando argumentos e justificativas próprias que permitam transferir para outras situações ou contextos.

- Usar do conhecimento matemático para comunicar suas opiniões e conclusões a respeito do tema em estudo.

- Interpretar a linguagem matemática, argumentar e se comunicar matematicamente.

- Realizar estimativas que podem ser auxiliadas pelo cálculo mental.

- Ser criativo, usar a lógica.

- Selecionar, organizar interpretar e avaliar criticamente as informações apresentadas.

- Pensar sobre o seu próprio pensar.

- Saber apresentar as informações matemáticas nas suas diferentes representações e ter senso crítico para avaliá-las.

- Realizar conexões entre os diversos campos do conhecimento.

Busca-se, na sequência, justificar a importância de desenvolver algumas dessas competências, iniciando-se com a competência da resolução de problemas, que se considera de fundamental importância por interferir e auxiliar em todas as outras áreas do conhecimento e, ainda, segundo o documento do NCTM (2008, p. 57):

Ao aprender a resolver problemas em matemática, os alunos irão adquirir 
modos de pensar, hábitos de persistência e curiosidade, e confiança perante situações desconhecidas, que lhes serão muito úteis fora da aula de matemática. Na vida quotidiana e no trabalho, ser hábil na resolução de problemas poderá acarretar muitas vantagens.

Argundín (2007, p. 40) destaca que na resolução de problemas:

Exercita-se a criatividade, a inovação de respostas, os novos procedimentos. Assim, as competências orientadas para a resolução de problemas permitem ao sujeito mobilizar seus recursos (saberes, capacidades, habilidades) para aplicá-los precisamente à resolução de problemas. (Tradução nossa).

Corroborando, Fernandes (1994, p. 137 apud AMADO, 2009, p. 2) afirma que “[...] a resolução de problemas deve ser o eixo de toda a educação matemática, uma vez que promove desenvolvimentos cognitivos de alto nível e o saber relacionar com o mundo real".

Ao trabalhar com a resolução de situações-problema, faz-se necessário que o professor incentive o aluno a questionar, a problematizar, a refletir sobre os dados apresentados, desenvolvendo, assim, o pensamento crítico, o qual, segundo Argundín (2007), permitirá discernir o certo do errado e comprometer o aluno com a construção de suas próprias competências.

Outra competência matemática fundamental é a comunicação matemática. Ela contribui para a consolidação e clarificação dos conceitos matemáticos, pois toda vez que alguém vai comunicar algo precisa rever seus conceitos, organizar suas ideias, testar suas conjecturas, refletir sobre o seu próprio pensamento e ainda sobre a forma como vai partilhar suas ideias.

As diferentes representações matemáticas, diagramas, gráficos, tabelas, expressões, segundo o documento do NCTM (2008), podem auxiliar os alunos a organizar melhor o seu pensamento e a comunicar-se de forma mais clara e objetiva, permitindo, assim, uma maior reflexão e uma tomada de decisão mais segura.

É fundamental que o aluno saiba avaliar a informação oferecida, pois, de acordo com Alarcão (2003, p. 13), a mídia, de forma geral, nos oferece muitas informações, porém nem todas são verdadeiras, sem falar que sua:

[...] influência é multifacetada, podendo ser usada para o bem e para o mal. As mensagens passadas apresentam valores, uns positivos, outros negativos, de difícil discernimento para aqueles que, por razões várias, não desenvolveram grande espírito crítico, competência que inclui o hábito de se questionar perante o que lhe é oferecido.

Por isso a importância de promover o desenvolvimento no aluno do senso crítico, de avaliar o que lê, saber onde procurar a informação, investigar, de não acreditar sem antes confirmar se uma informação é verdadeira ou não, buscar diferentes pontos de vista sobre um mesmo tema e só a partir da análise de todas estas visões definir uma opinião. Segundo 
Hargreaves (2004, p. 34), “A chave para uma economia do conhecimento forte, entretanto, não é apenas as pessoas poderem acessar a informação, mas também o quão bem elas conseguem processar essa mesma informação".

Segundo Homer-Dixon (apud HARGREAVES, 2004, p. 38), a sociedade precisa que os alunos tenham muita inventividade, definida por ele como:

[...] ideias que possam ser aplicadas para resolver problemas práticos, técnicos e sociais, tais como aqueles que surgem a partir da poluição da água, erosão de terras cultiváveis e coisas do tipo. A inventividade inclui não apenas ideias verdadeiramente novas, muitas vezes chamadas de "inovações", mas também aquelas que, não sendo fundamentalmente novas, são todavia úteis.

Ao longo da escolarização, os alunos vão se apropriando de conceitos, propriedades, teoremas, algoritmos, diferentes modos de pensar matematicamente, sendo necessário estabelecer conexões entre estes pensamentos e entre os diferentes contextos exteriores, até mesmo a própria Matemática. Isso pode facilitar a compreensão dos conceitos, tornando-os mais duradouros.

$\mathrm{Na}$ área da Matemática, também se faz necessário desenvolver competências que são específicas de cada um dos quatro blocos de conteúdos.

A partir da leitura dos Parâmetros Curriculares Nacionais (BRASIL, 1998), Matriz de Referência do SAEB (BRASIL, 2011), do documento do NCTM (2008) e do Referencial Curricular do Estado do Rio Grande do Sul (RIO GRANDE DO SUL, 2009), verificou-se que a apresentação dos conteúdos está organizada em blocos. A organização dos conteúdos e nomenclatura dos blocos difere de documento para documento, porém verifica-se que as competências matemáticas esperadas para o aluno egresso do Ensino Fundamental são semelhantes, por isso optou-se por apresentá-las de acordo com a seguinte categorização: Números e Operações, Álgebra, Geometria e Medidas e Tratamento da Informação.

O bloco "Números e Operações" visa a conhecer e compreender os diferentes números (naturais, inteiros, racionais e irracionais), bem como os seus diferentes significados, as formas de representação, as propriedades, a relação entre eles e como realizar as operações.

Busca-se, no documento produzido pelo NCTM (2008, p. 34), justificativa para trabalhar com este bloco de conteúdos:

Historicamente, o número tem sido a pedra angular de todo o currículo de Matemática, [...]. Toda a Matemática do pré-escolar ao $12^{\circ}$ ano tem estado solidamente baseada no número. Os princípios que regem a resolução de equações, na álgebra, são os mesmos das propriedades estruturais dos sistemas numéricos. Na geometria e na medida, os atributos são descritos através de números. A totalidade da análise de dados envolve o sentido do número. Através da resolução de problemas, os alunos podem explorar e consolidar a 
sua compreensão do número. É bastante provável que os primeiros raciocínios matemáticos das crianças envolvam situações numéricas e as suas primeiras representações são números.

A partir da citação, verifica-se que os Números e as Operações são imprescindíveis para o trabalho nos demais blocos de conteúdos, servindo de instrumento para resolver as diferentes situações do dia a dia.

O bloco "Tratamento da Informação" visa a estudar noções de Estatística e de Probabilidade, além dos problemas de contagem que envolvem o princípio multiplicativo; busca selecionar, organizar, representar em tabelas e gráficos os dados, interpretá-los e elaborar conclusões a partir da leitura e análise dos mesmos.

Shaughnessy (1996 apud CARVALHO, 2014, p. 36) ressalta que:

[...] ser competente em Estatística é essencial aos cidadãos das sociedades atuais: para ser crítico em relação à informação disponível na sociedade, para entender e comunicar com base nessa informação, mas, também, para tomar decisões, atendendo a que, uma grande parte da organização dessas mesmas sociedades, é feita com base nesses conhecimentos.

O bloco "Álgebra”, segundo os Parâmetros Curriculares Nacionais (BRASIL, 1998), é mais explorado a partir do $8^{\mathrm{a}}$ ano, e procura obter padrões aritméticos, estabelecer relação entre duas grandezas, tomar contato com fórmulas, traduzir situações-problema por meio de equações ou inequações, compreendendo as regras para resolução das mesmas, o que facilitará a exploração da noção de função, calcular o valor numérico e efetuar operações com expressões algébricas, utilizando as propriedades conhecidas, realizando fatorações e simplificações.

A álgebra permite que ideias matemáticas complexas possam ser expressas sucintamente, facilitando a resolução. E, ainda, segundo o documento do NCTM (2008, p. 39):

[...] os métodos e as ideias algébricas fundamentam o trabalho matemático em muitas áreas. Por exemplo, as redes de distribuição e comunicação, as leis da física, os modelos populacionais e os resultados estatísticos podem, todos eles, ser representados na linguagem simbólica algébrica. Além disso, a álgebra trata de estruturas abstratas e da utilização dos respectivos princípios na resolução de problemas expressos através de símbolos.

Além disso, a Álgebra se faz presente no ensino da Geometria, facilitando o registro das ideias, a resolução de problemas, sem falar que a Álgebra está cada vez mais presente nas tecnologias informáticas, situação em que se faz necessário que o aluno as use para produzir fórmulas matemáticas que irão gerar tabelas estatísticas com mais facilidade.

A Geometria, de acordo com os Parâmetros Curriculares Nacionais (BRASIL, 1998, p. 51), auxilia o aluno a "[...] compreender, descrever e representar, de forma organizada, o mundo em que vive". E as medidas auxiliam o aluno a utilizar instrumentos adequados para medir e 
explorar diferentes grandezas: comprimento, massa, tempo, capacidade e temperatura. Por isso, este bloco de conhecimento visa a ampliar e construir noções de medida, sabendo realizar as devidas conversões, construir a noção de ângulo, paralelismo, perpendicularidade, reconhecer e caracterizar as figuras planas, sabendo calcular a área das mesmas e o volume de prismas.

De acordo com Sherard III (2015), a Geometria é uma competência básica, porque ajuda na comunicação escrita e falada, facilitando a localização, a descrição de objetos e a comunicação do mundo que nos cerca, estando presente na arte, nas construções e na natureza. Porque se faz necessária na realização de medidas dentro e fora de casa, ajuda na leitura de mapas, está presente em tópicos da Matemática básica, sendo um tema unificador em todo o currículo da Matemática. Serve de base para tópicos mais avançados, servindo de pré-requisito.

Além de desenvolver competências que visam ao desenvolvimento do aluno nos quatro pilares da educação - ser, conviver, fazer e conhecer, e competências matemáticas tanto no âmbito geral quanto as específicas dos blocos de conteúdos -, temos que ter clareza que o mundo está mudando muito depressa, e o que hoje se julga prioritário que o aluno saiba, amanhã pode ser superado por outras necessidades. Conforme afirma Pérez Gómez (1994), hoje as crianças e os adolescentes têm uma visão diferente do tempo, do espaço e das relações, comparando-se com a visão das pessoas de vinte anos atrás. As suas necessidades e expectativas são influenciadas pelo meio em que vivem.

Schoenfeld (1985 apud GODED, 1997) acredita que é necessário ensinar o aluno como pensar matematicamente sobre o mundo, como ver o mundo com olhos matemáticos.

Levando tudo isso em consideração, realizou-se uma pesquisa nas escolas estaduais do estado do Rio Grande do Sul pertencentes à $15^{\mathrm{a}} \mathrm{CRE}$, visando conhecer o currículo dessas escolas e propor indicativos para a elaboração de uma proposta de currículo de Matemática para os alunos do $6^{\circ}$ ao $9^{\circ}$ ano do Ensino Fundamental, objetivando o desenvolvimento de tais competências. Na sequência apresenta-se a metodologia empregada na pesquisa.

\section{Metodologia da Pesquisa}

O Estado do Rio Grande do Sul possui trinta Coordenadorias Regionais de Educação (CRE), sendo cada uma delas responsável pelas políticas relacionadas a sua região de abrangência, tendo como atribuição coordenar, orientar e supervisionar as escolas, oferecendo suporte administrativo e pedagógico. Isso inclui a nomeação ou contratação de profissionais para trabalhar nas escolas, sejam eles professores ou funcionários. A presente investigação é um estudo de caso e tem como foco a $15^{\text {a }}$ CRE do estado do Rio Grande do Sul. 
A referida coordenadoria é a maior em extensão do estado do Rio Grande do Sul, compreendendo 41 municípios localizados nas regiões norte e nordeste do estado gaúcho. Possui 113 escolas, sendo que 86 delas atendem os anos finais do Ensino Fundamental.

Conforme já destacado, a pesquisa teve como objetivo geral apresentar indicativos para uma proposta de currículo de Matemática para os Anos Finais do Ensino Fundamental que privilegie o desenvolvimento das competências necessárias para a formação de um cidadão comprometido e atuante para a região de abrangência da $15^{\mathrm{a}} \mathrm{CRE}$. A fim de atingir o objetivo proposto, o estudo constou de cinco etapas: levantamento do referencial teórico; coleta dos dados e caracterização da região estudada; análise dos dados; definição de habilidades e competências mínimas que devem ser desenvolvidas do $6^{\circ}$ ao $9^{\circ}$ ano do Ensino Fundamental; e apresentação de indicativos para a elaboração de uma proposta de currículo que privilegie o desenvolvimento de competências para os Anos Finais do Ensino Fundamental da região da $15^{\text {a }}$ CRE na área de Matemática.

A partir da triangulação destes dados fez-se a proposição de alguns indicativos a serem pensados em uma possível elaboração de um currículo que privilegie o desenvolvimento de competências para os Anos Finais do Ensino Fundamental da região da $15^{\mathrm{a}} \mathrm{CRE}$ na área da Matemática.

\section{Refletindo Indicativos Para Uma Proposta De Currículo Que Privilegie O Desenvolvimento De Competências}

Diante do conhecimento da realidade educacional da região investigada, foram propostos indicativos para a elaboração de uma proposta de currículo que privilegie o desenvolvimento de competências para a área de Matemática em alunos do $6^{\circ}$ ao $9^{\circ}$ ano do Ensino Fundamental da região estudada, dentre os quais destacam-se:

1. Maior incentivo aos professores para ampliarem a sua formação e participarem de formações continuadas e eventos, pois acredita-se que uma formação qualificada dos professores pode vir a contribuir de forma mais efetiva na proposição de situações de aprendizagem que possam desenvolver um currículo com foco no desenvolvimento de competências nos estudantes.

Sugere-se que os professores ampliem sua formação, pois verificou-se que $74 \%$ dos mesmos têm formação em nível de graduação, o que habilita a trabalhar a disciplina de Matemática na Educação Básica; 38,5\% têm Especialização; e apenas 1,1\% dos professores 
investigados têm Mestrado.

Já quanto à formação continuada, verificou-se que 94,3\% dos professores participaram de algum tipo de formação continuada nos anos de 2013 e 2014. Porém, verificou-se que algumas das formações destacadas pelos professores não surtiram efeito na prática da sala de aula. É o caso, por exemplo, do uso de diferentes metodologias, destacado pelos professores como um tema trabalhado em diferentes formações continuadas. Mesmo assim, 60\% dos professores afirmaram usar diferentes metodologias (de 1\% a 20\%) em suas aulas. E, ainda, apesar de afirmarem ter participado de formações sobre os temas currículo e competência, verificou-se que uma parcela significativa dos professores teve dificuldade para conceituar esses termos.

Segundo Imbernón (2009), isso nos faz refletir sobre as formações continuadas que estão sendo realizadas. $\mathrm{O}$ autor acredita que muito se fala em mudanças no ensino, entretanto as mudanças estão se restringindo à fala e não sendo aplicadas na prática.

Imbernón (2009, p. 40-41) acredita, ainda, que seja importante:

Criar estruturas (redes) organizativas que permitam um processo de comunicação entre os pares e intercâmbio de experiências para possibilitar a atualização em todos os campos de intervenção educativa e aumentar a comunicação entre o professorado para refletir sobre a prática educativa mediante a análise da realidade educacional, a leitura pausada, o intercâmbio de experiências, os sentimentos sobre o que acontece, a observação mútua, os relatos de vida profissional, os acertos e erros... que possibilitem a compreensão, a interpretação e a intervenção sobre a prática.

Imbernón (2009) acredita que, ao serem realizadas formações continuadas, é importante que se reflita sobre a prática, levando em consideração o contexto em que a escola está inserida e a opinião dos professores. Para tanto, acredita-se que é importante que os docentes participem da decisão do tema sobre o qual será realizada a formação continuada, optando por temas que tenham mais necessidade ou ainda temas que tenham a ver com os projetos que a escola tem e sobre os quais se careça de conhecimentos para desenvolver.

Quanto aos eventos, verificou-se que apenas 48,3\% dos professores informaram ter participado dos mesmos nos anos de 2013 e 2014, e acredita-se ser importante a participação em eventos, visto que os professores, além de trocarem informações e experiências, podem trazer contribuições para a escola como um todo.

\section{Definição das competências que a escola espera que o aluno egresso do Ensino Fundamental} possua, porque a partir disso é possível definir estratégias, atividades, projetos, enfim, ações que possam contribuir para que o aluno alcance tais competências. 
Destaca-se a importância de desenvolver atividades em sala de aula que visem desenvolver no aluno os quatro pilares propostos pela UNESCO: aprender a ser, aprender a conhecer, aprender a conviver e aprender a fazer.

E, para isso, pode-se perguntar: Como a Matemática pode contribuir com o desenvolvimento do aluno como um todo? Como é possível desenvolver tais competências?

Para auxiliar em tal desenvolvimento é importante que o professor priorize o desenvolvimento de atitudes coerentes, promova a participação de todos os alunos, criando um clima cooperativo na sala de aula, em que os alunos se sintam acolhidos, tenham coragem de dar opiniões e perceberem que a mesma é respeitada, tanto pelos colegas quanto pelo professor.

De acordo com os Parâmetros Curriculares Nacionais (BRASIL, 1998, p.30), a Matemática pode contribuir para a formação ética dos alunos:

[...] à medida que o professor valorizar a troca de experiências entre os alunos como forma de aprendizagem, promover o intercâmbio de ideias como fonte de aprendizagem, respeitar ele próprio o pensamento e a produção dos alunos a desenvolver um trabalho livre do preconceito de que Matemática é um conhecimento direcionado para poucos indivíduos talentosos.

A referida disciplina também pode contribuir com “[...] a formação do cidadão ao desenvolver metodologias que enfatizem a construção de estratégias, a comprovação e justificativa de resultados, a criatividade, a iniciativa pessoal, o trabalho coletivo e a autonomia advinda da confiança na própria capacidade para enfrentar desafios". (BRASIL, 1998, p. 27).

A Matemática pode, também, contribuir para que o aluno aprenda a conviver na sociedade. Para isso é importante que o professor proponha trabalhos em grupo, nos quais o aluno perceba a importância de saber ouvir, respeitar a opinião dos outros, saber trabalhar em equipe, favorecendo assim o desenvolvimento da capacidade do aluno de viver harmonicamente em sociedade, respeitando as diferenças. De acordo com os Parâmetros Curriculares Nacionais (BRASIL, 1998, p. 27), é importante que a escola desenvolva uma educação "[...] que não dissocie escola de sociedade, conhecimento e trabalho, e que coloque o aluno ante desafios que lhe permitam desenvolver atitudes de responsabilidade, compromisso, crítica, satisfação e reconhecimento de seus direitos e deveres".

Espera-se que os professores de Matemática integrem os blocos de conteúdos, procurando fazer com que o aluno aprenda a observar a Matemática como "[...] um corpo unificado de conhecimentos, em vez de um conjunto complexo de conceitos, procedimentos e processos isolados" (NCTM, 2008), mostrando assim aplicações de tais conteúdos na área da Matemática como um todo e, também, em outras áreas do conhecimento.

São destacadas a seguir algumas dessas competências: resolver, tanto individualmente 
como em grupo, problemas da vida cotidiana, de outras ciências ou da própria Matemática, utilizando diferentes estratégias e aplicando os resultados na resolução de novas situações; identificar, relacionar, descrever e representar os elementos matemáticos presentes no dia a dia e no meio científico, analisando criticamente as informações que eles querem transmitir; raciocinar e argumentar matematicamente, elaborando argumentos e justificativas próprias que permitam transferir para outras situações ou contextos; usar do conhecimento matemático para comunicar suas opiniões e conclusões a respeito do tema em estudo; realizar estimativas que podem ser auxiliadas pelo cálculo mental; ser criativo; usar a lógica; selecionar, organizar, interpretar e avaliar criticamente as informações apresentadas; pensar sobre o próprio pensar.

3. Ensino em Turno Integral, porque ao realizar-se uma reflexão sobre as competências que o aluno precisa ter a fim de se tornar um cidadão competente e atuante na sociedade atual, desenvolvendo-se nos quatro pilares propostos pela UNESCO, bem como a necessidade de desenvolver diferentes atividades para que isso aconteça, nos faz acreditar que a escola, da forma como está estruturada atualmente, não conseguirá dar conta de realizar tal trabalho.

Para trabalhar um ensino em turno integral, numa jornada como indicam as Diretrizes Curriculares Nacionais para a Educação Básica (BRASIL, 2013), que são no mínimo sete horas, é necessário que se reflita como, efetivamente, isso vai acontecer, quais são os níveis que serão atendidos nesta proposta, quais são as mudanças que deverão ser realizadas na escola, no currículo, qual o perfil de aluno que se espera formar, quem serão os profissionais que irão acompanhar os alunos em cada uma das atividades propostas, em que espaço cada atividade irá acontecer, qual será a participação da comunidade escolar como um todo, como serão atendidos os alunos que têm deficiência ou dificuldades de aprendizagem, como serão acolhidas as diferentes culturas, que competências querem desenvolver no aluno de uma forma geral, que projetos a escola vai desenvolver e como vai envolver a comunidade educativa, ou seja, os alunos, os pais, os professores, os funcionários, as coordenações e as direções, nesses projetos, como vai priorizar o trabalho interdisciplinar e o trabalho com temas transversais. Ou seja, para pensar em um ensino em turno integral faz-se necessário rever e reorganizar o currículo como um todo.

Para que isso aconteça, é necessário que os gestores da escola oportunizem momentos para que todos os professores se reúnam, revisem, definam as competências que esperam que os alunos atinjam em cada série ao final do Ensino Fundamental e elaborem os grandes projetos da escola. Da mesma forma, é importante que se oportunize momentos nos quais os professores 
se reúnam por área e também por série em que atuam, para pensar em como trabalhar os projetos propostos pela escola, elaborar atividades próprias da área, verificar se é possível organizar projetos interdisciplinares ou trabalhar com temas transversais de forma conjunta, realizar avaliações das atividades propostas, verificar se as mesmas estão auxiliando o aluno a se desenvolver como um todo: ser, conhecer, conviver e fazer, avaliando se há algum aluno que não está atingindo as competências esperadas, o que fazer, que estratégias usar, a fim de que ele as alcance.

Atividades como estas são fundamentais em uma escola. Os professores precisam dialogar, construir juntos o currículo da escola, decidir e traçar metas, definir as competências a serem alcançadas, enfim, os professores precisam trabalhar em equipe e em conjunto com os segmentos da comunidade escolar.

Quando se refere que os professores precisam trabalhar em equipe, refere-se a um trabalho sistemático, no qual os gestores organizem horários no turno de trabalho dos docentes para que isso seja possível. Verificou-se, a partir das respostas dos professores de Matemática da $15^{\mathrm{a}} \mathrm{CRE}$, que um dos motivos pelos quais eles afirmam não trabalhar em equipe é não ter um horário comum no seu turno de trabalho para realizar as reuniões, para fazer planejamentos coletivos e planejarem projetos comuns.

A proposta deste estudo é que a escola trabalhe pela manhã as disciplinas obrigatórias em salas-ambiente e, à tarde, sejam oferecidas oficinas.

Tanto em um turno quanto em outro é importante que se varie as metodologias, que se propicie momentos em que o aluno trabalhe individualmente; outros que trabalhe em grupos ou coletivamente, sendo as equipes heterogêneas ou homogêneas. De acordo com Zabala e Arnau (2010), os alunos têm ritmos diferentes e necessidades específicas. Enquanto uma modalidade de trabalho pode ser muito produtiva para um aluno em um determinado momento, para outro pode não ser, mas se a aula for diversificada, a probabilidade de atingir positivamente um maior número de alunos aumenta consideravelmente.

Quanto ao professor, faz-se necessário que ele também varie a sua forma de intervenção. Alguns conteúdos e/ou metodologias requerem que o professor seja mais diretivo; porém há outros nos quais o professor pode ser mais participativo, cooperativo, um mediador do processo de ensino e aprendizagem. 


\section{Considerações Finais}

Para finalizar, ressalta-se a importância dos gestores da escola, em um trabalho conjunto com a comunidade escolar (professores, alunos, pais, direção, funcionários), delimitarem claramente o conjunto de competências que acreditam serem essenciais que o aluno egresso do Ensino Fundamental possua. Isso facilitará a elaboração de estratégias, atividades, projetos, entre outros.

Ao definir tais competências, a comunidade educativa precisa visar ao desenvolvimento do aluno como um todo, ou seja, que ele aprenda a ser, conhecer, conviver e fazer, sendo para isso essencial um trabalho em equipe por parte de todos os envolvidos na escola.

No que tange à disciplina de Matemática, observou-se que existem competências que todos os blocos de conteúdos podem contribuir para o desenvolvimento, tais como: raciocinar e interpretar logicamente problemas, argumentar matematicamente, elaborando justificativas próprias que permitam transferir para outras situações ou contextos, fazer estimativas, comunicar com clareza suas opiniões utilizando a linguagem matemática de forma correta, realizar conexões entre os diversos campos do conhecimento, entre outras. E existem competências próprias de cada um dos blocos de conhecimento, porém, sempre que possível os professores devem propiciar atividades que envolvam e interliguem os blocos de conteúdos.

A partir da pesquisa realizada constatou-se a necessidade de propiciar mais incentivos aos professores para ampliarem a sua formação, participando de formações continuadas e eventos, bem como de o ensino ser em Turno Integral, acreditando que assim será mais fácil desenvolver as competências delimitadas pela escola.

Acredita-se que para trabalhar o ensino em Turno Integral é fundamental que os professores trabalhem em equipe, pensando em projetos, avaliando constantemente a caminhada, os objetivos propostos, planejando continuamente novas atividades, sendo necessário, para isso, que os gestores oportunizem momentos para que os professores realizem tais atividades.

\section{Referências}

ALARCÃO, I. Professores Reflexivos em uma Escola Reflexiva. Cortez, 2003. 
AMADO, N.; AMARAL, N.; CARREIRA, S. A liberdade que as tecnologias permitem: trabalhando os números e as capacidades matemáticas transversais. In: ENCONTRO DE INVESTIGAÇÃO EM EDUCAÇÃO MATEMÁTICA, 19, Vila Real, Portugal. Anais eletrônicos... Vila Real, 2009. Disponível em:

$<$ http://spiem.pt/DOCS/ATAS_ENCONTROS/2009/GD3/2009_22_NAmado_NAmaral_SCarreira.pdf >. Acesso em: 20 set. 2014.

ARGUDÍN,Y. Educación basada en Competencias: Nociones y Antecedentes. México: Trillas, 2007.

BRASIL. Ministério da Educação. Secretaria de Educação Básica. Secretaria de Educação Continuada, Alfabetização, Diversidade e Inclusão. Secretaria de Educação Profissional e Tecnológica. Conselho Nacional da Educação. Câmara Nacional de Educação Básica. Diretrizes Curriculares Nacionais Gerais da Educação Básica. Ministério da Educação. Secretaria de Educação Básica. Diretoria de Currículos e Educação Integral. Brasília: MEC, SEB, DICEI, 2013.

Portal INEP. Disponível em: <http://portal.inep.gov.br/web/saeb/matrizes-dereferencia-professor>. Acesso em: 10 set. 2011.

Ministério da Educação. Parâmetros Curriculares Nacionais para o Ensino

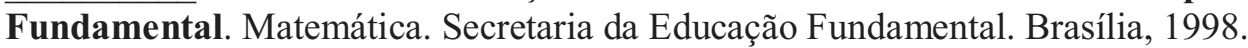

CARVALHO, C. Literacia estatística. Disponível em: <

http://miniweb.com.br/Educadores/artigos/pdf/estatica-portugal.pdf >. Acesso em: 20 set. 2014.

CONSEJO EUROPEO. Common European Framework of Reference for Languages: Learning, teaching, assessment. Cambridge: University Press, 2001. (Trad. Cast.: Marco común europeo de referencia para las lenguas: aprendizaje, enseñanza, evaluación. Madrid. Instituto Cervantes, 2002).

DELORS, J. (Coord.). EDUCAÇÃO: um tesouro a descobrir - Relatório para a UNESCO da Comissão Internacional sobre Educação para o século XXI. São Paulo: Cortez, 1996.

GODED, P. A. ¿Qué matemáticas necesitamos para comprender el mundo actual? Investigacíon en la Escuela. Espanha, n. 32, p. 77-86, 1997.

. La naturaleza de la matemática escolar: problema fundamental de la didáctica de la matemática. Investigación en la Escuela. Espanha, n. 24, p. 79-87, 1994.

GÓMEZ, Á. I. P. Competências ou pensamento prático? A construção dos significados de representação e de ação. In: SACRISTÁN, J. G. et al. Educar por competências: o que há de novo? Porto Alegre: Artmed, 2011. p. 64-114.

HARGREAVES, A. O ensino na sociedade do conhecimento: educação na era da insegurança. Porto Alegre: Artmed, 2004.

IMBERNÓN, F. Formação permanente do professorado: novas tendências. São Paulo: Cortez, 2009.

MACHADO, N. J. Educação: competência e qualidade. 2. ed. São Paulo: Escrituras, 2010. (Coleção Ensaios Transversais, 37).

NCTM. Princípios e Normas para a Matemática Escolar. Lisboa: Associação de Professores de Matemática, 2008.

OCDE. La Evaluación de la Competencia Matemática: Marco Conceptual Pisa, 2012. Disponível em: < 
http://www.anep.edu.uy/anep/phocadownload/pisa/pisa2012/Informestematicos/Matematica\%20en\%2 0PISA\%202012.pdf >. Acesso em: 7 set. 2015.

Programa para La Evaluación Internacional de Alumnos de La OCDE. Informe Español. 2006. Disponível em: < http://www.educacion.gob.es/multimedia/00005713.pdf $>$. Acesso em: 01 out. 2011.

Proyecto: Definitions et selection des competences. Fondements theoriques et conceptuels. Document de strategie. DEELSAIED/CERI/CD, 2002. Disponível em:

$<$ http://www.deseco.admin.ch/bfs/deseco/en/index/03/02.html >. Acesso em: 12 out. 2014.

PÉREZ, GÓMEZ, R. La cultura escolar en la sociedad posmoderna. Cuadernos de Pedagogía. Madrid, España, n. 225, p. 80-85, 1994.

PERRENOUD, P. Desenvolver competências ou ensinar saberes? A escola que prepara para a vida. Porto Alegre: Penso, 2013.

Construir competências desde a escola. Porto Alegre: Artes Médicas Sul, 1999.

PERRENOUD, P. et al. As competências para Ensinar no século XXI: a formação dos professores e o desafio da avaliação. [recurso eletrônico]. Porto Alegre: Artmed, 2007.

RIO GRANDE DO SUL. Secretaria de Estado da Educação. Referenciais Curriculares do Estado do Rio Grande do Sul: Matemática e suas Tecnologias. Secretaria de Estado da Educação. Porto Alegre, 2009.

SHERARD III, W. Por que a Geometria é uma competência básica? Disponível em: < https://pactuando.files.wordpress.com/2014/10/texto-por-que-geometria-c3a9-uma-competc3aanciabc3a1sica.pdf >. Acesso em: 24 jan. 2015.

ZABALA, A; ARNAU, L. Como aprender e ensinar competências. Porto Alegre: Artmed, 2010. 